\title{
Гибридный волоконно-полупроводниковый лазер с электрооптическим ответвителем для генерации импульсов произвольной формы
}

\author{
$\underline{\text { Б.Н. Нюшков }}^{1,2, *}$, А.В. Иваненко ${ }^{1}$, С.В. Смирнов ${ }^{1}$, С.М. Кобцев ${ }^{1}$ \\ ${ }^{1}$ Новосибирский государственный университет \\ ${ }^{2}$ Новосибирский государственньй технический университет \\ *E-mail: b.nyushkov@nsu.ru
}

DOI: 10.31868/RFL2020.71-72

Генерация лазерных импульсов с произвольно-задаваемой формой и структурой является одной из актуальнейших задач лазерной физики [1]. В данной работе представлен новый подход к электронно-управляемой генерации наносекундных лазерных импульсов произвольной формы в гибридного волоконнополупроводникового лазере с использованием волноводного электрооптического ответвителя (ВЭО) на основе $\mathrm{LiNbO}_{3}$. Схема лазера представлена на Рис. 1 (а). В наших предыдущих работах [2, 3] уже демонстрировались возможности электронного управления формой и структурой импульсных паттернов в подобных волоконно-полупроводниковых лазерах с постоянными ответвителями посредством модуляции усиления в режиме синхронной накачки. Однако такой режим накладывает существенные ограничения на допустимый тайминг лазерных импульсов, который определяется временем обхода резонатора и должен соответствовать строго-определенному дискретному набору частот повторения. Новый подход предполагает использование четырех-портового ВЭО, электронное управление комплементарной передаточной характеристикой которого в сочетании с быстрым ( 1 нс) откликом полупроводниковой усиливающей среды, позволяют реализовать уникальный режим генерации [4] близкий по своей сути к разгрузке резонатора, однако полностью свободный от каких либо ограничений по таймингу лазерных импульсов. Рис. 1 (б) демонстрирует область существования такого режима в зависимости от напряжения, управляющего ВЭО, т.е. область, в которой внутрирезонаторная мощность, измеряемая на входе в ВЭО, насыщается и слабо зависит от степени открытия ВЭО наружу резонатора).
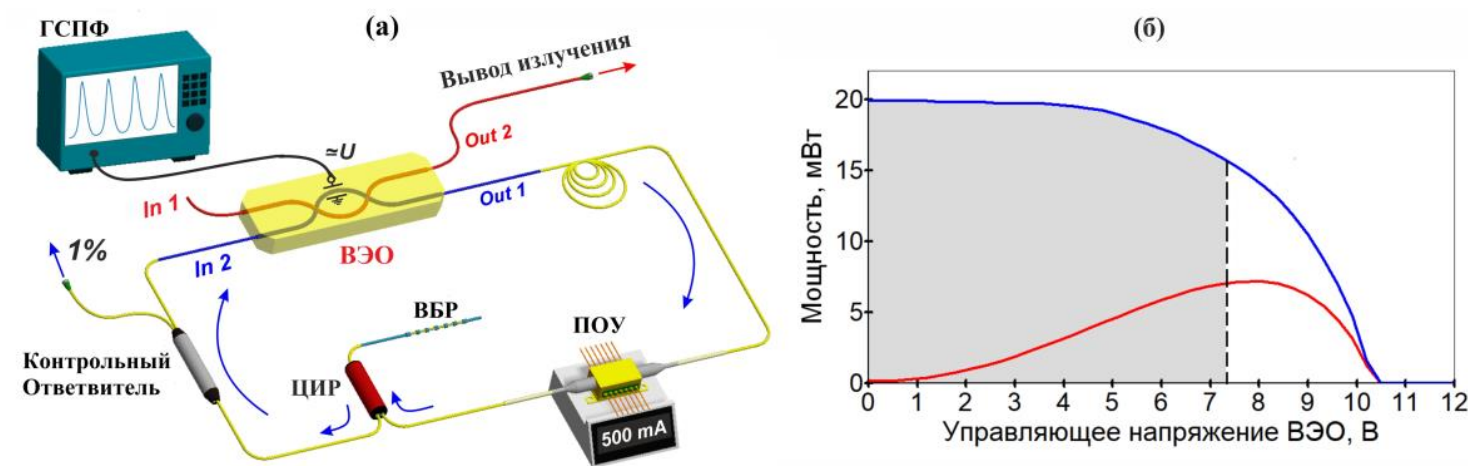

Рис. 1. (а) Схема лазера с ВЭО: ГСПФ - генератор сигналов произвольной формы, ПОУ - полупроводниковый оптический усилитель, ВБР - волоконная брэгговская решетка, ЦИР-циркулятор. (б) Зависимость внутрирезонаторной и выгружаемой с помощью ВЭО мощности излучения генерации от напряжения управляющего открытием ВЭО (синяя и красная кривая соответственно).

Закрашенная область соответствует динамическому диапазону, используемому для формирования лазерных импульсов произвольной формы в режиме квази-разгрузки резонатора.

Нами показано, что электронное управление ВЭО в указанном режиме открывает возможности для генерации лазерных импульсов произвольной формы 
(Рис. 2 (a)) с произвольно-задаваемой частотой следования, которую можно варьировать от 0 (одиночный импульс) до нескольких десятков МГц. Периодические последовательности таких произвольных импульсов характеризуются высоким качеством радиочастотных спектров (Рис. 2(б)), сопоставимым с классическими волоконными лазерами в режиме синхронизации мод. Продемонстрирована также возможность качания частоты следования импульсов. Быстродействие используемого ВЭО обеспечивает $\sim 10$ нс разрешение для формирования лазерных сигналов произвольной формы. Существующие на сегодняшний день технологии создания быстродействующих ВЭО потенциально позволяют добиться субнаносекундного разрешения при формировании лазерных импульсов указанным способом. Стоит отметить также энергоэффективность предложенного способа формирования лазерных импульсов произвольной формы, поскольку такое профилирование импульсов не основывается на управляемой диссипации энергии излучения, как например, в случае применения модуляторов интенсивности.

Предложенный подход открывает новые перспективы для различных областей науки и техники.
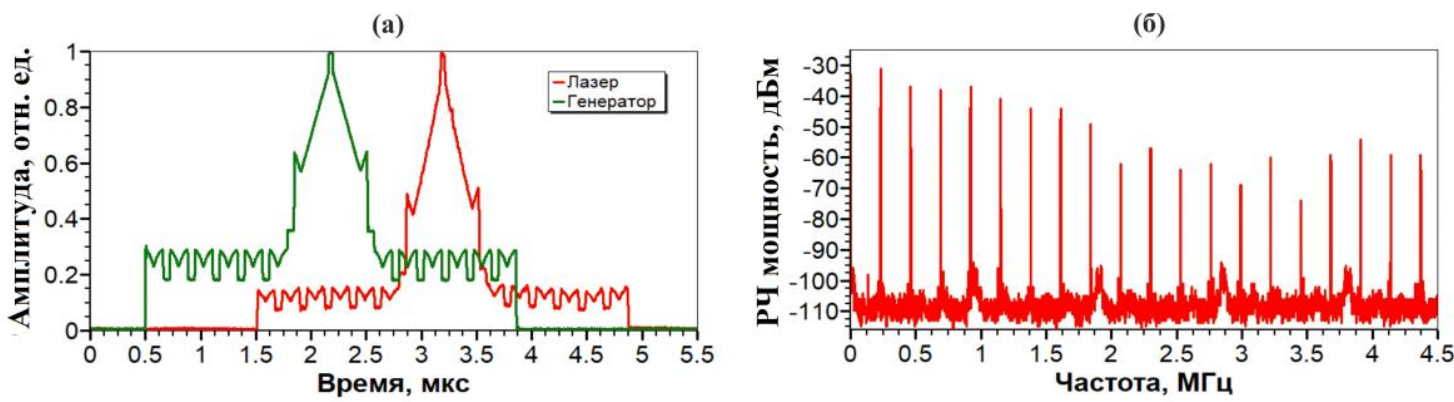

Рис. 2. Осциллограммы задающего (зеленая кривая) и генерируемого лазером (красная кривая) импульсов специальной формы (а) и радиочастотный спектр регулярной последовательности таких лазерных импульсов (б).

Работа выполнена при частичной поддержке Министерства науки и высшего образования РФ (FSUN-2020-0007) и Российского фонда фундаментальных исследований (проекты 18-32-20021 и 18-29-20025).

\section{Литература}

[1] D. D. Yavuz, Science 331, 1142-1143 (2011)

[2] B. Nyushkov, A. Ivanenko, S. Smirnov, S. Kobtsev, Laser Phys. Lett. 16, 115103 (2019)

[3] B. Nyushkov, S. Kobtsev, A. Ivanenko, S.Smirnov, J. Opt. Soc. Am. B 36, 3133-3138 (2019)

[4] B. Nyushkov, A. Ivanenko, S. Smirnov, O. Shtyrina et al, Opt. Express 28, 14922-14932 (2020) 